\title{
Cyber-victimization and perceived depression: Serial mediation of self-esteem and learned-helplessness
}

\author{
Kususanto Prihadi, Yen Ling Hui, Melissa Chua, Calvin K.W. Chang \\ Center of Cyberpsychology and Games, Dept. of Psychology, HELP University, Malaysia
}

\begin{tabular}{l} 
Article Info \\
\hline Article history: \\
Received Jul 31, 2019 \\
Revised Oct 23, 2019 \\
Accepted Nov 22, 2019 \\
\hline
\end{tabular}

\section{Keywords:}

Cyber-victimization

Learned helplessness

Perceived depression

Social media

State self-esteem

\begin{abstract}
Literature suggests that the perception of being cyber-victimized is a stronger predictor of depression symptoms than the perception of being victimized offline, and that learned-helplessness can explain the prediction of perceived cyber-victimization on perceived depression. Nevertheless, other studies suggested that the link between perceived cyber-victimized and learnedhelplessness is weakened by state self-esteem. This study investigates the double mediation effect of state self-esteem and learned-helplessness on the relationship between perceived cyber-victimized and perceived depression. 104 participants between 18 and 30 years of age (63 females, 41 males, 1 prefer not to say) have been recruited through haphazard sampling method to fill in the Cyberbullying Victimization Scale, State Self-Esteem Scale, Learned Helplessness Scale, and Beck's Depression Inventory. Our findings suggest that the double mediation effect occurs. As a conclusion, our findings suggested that cyberbullied social media users will only fall into perceived depression when their state self-esteem is also negatively affected by their perception of being cyberbullied, up to the point where they learn that they are helpless. Further implication are discussed at the end of the paper.
\end{abstract}

Copyright $(\odot) 2019$ Institute of Advanced Engineering and Science. All rights reserved.

\section{Corresponding Author:}

Kususanto Prihadi,

Department of Psychology,

HELP University,

No. 2, Persiaran Cakerawala, Section U4, 401050 Shah Alam, Selangor, Malaysia.

Email: prihadi.k@help.edu.my

\section{INTRODUCTION}

Changes constantly take place in terms of the way adolescents and young adults communicate [1] because social media enables everyone to have easy access to stay connected with one another [2]. Social media is currently a major medium of communication and information [3], and it has some distinct features that could not be found in face-to-face communication, such as its everlasting accessibility, where users can expect attention and positive comments or "likes" anytime from practically anybody in the world [4]; in turn, receiving such feedback might improve one's internal control and self-esteem [5].

Involvement in social media activities also has its consequences, such as negative judgment [6], which can lead to verbal aggression or also known as cyberbullying [7]. While every social media user might be vulnerable to such aggression, not everyone will experience it, because not all of them are "chosen" by the offenders [8]. The perspective of traditional victimology perspectives can explain how relationship between victims, offenders, and the environment itself might induce cyberbullying $[9,10]$ the traditional routine activities model states that victimization might take place when a targeted victim and a motivated offender converge in a place without meaningful surveillance or capable guardians [9]. In the context of cyber space, social media facilitates the convergence of suitable victims and motivated offenders.

One of the indicators of the absence of guardianship is how free the youth and adolescence behave on social media; for instance, $20 \%$ of teenagers admitted having shared or posted nude or seminude photos of themselves [10], while $40 \%$ of teens and young adults reported that they have been shown a sexually suggestive 
message originally meant for someone else [11]. This proactive disclosure culture enables any social media user to identify suitable victims by obtaining the personal information that would seldom be released on consent in an offline context [8]. Moreover, users can choose to be anonymous and get away with their aggressive online behavior $[12,1]$ when there is a lack of adequate mechanisms provided by either lawmakers or technology providers for identifying, arresting, or prosecuting cyberbullies [13], and most of the time, cybervictimization cases are underreported [14].

Apart from that, social media communication also intensifies the negative impacts of cyber victimization [13]. First, because users do not start using social media with an intention to make new friends, they merely replicate their offline social environment in the online realm $[15,16]$ which means that their group dynamic remains the same; the victims and the bullies retain their social roles online, and due to the 24/7 accessibility, social media amplifies the negative social capital that might have already taken place in their offline social environment. For instance, when cyber-victimization attempt was directed towards individuals who are not used to be victimized offline, reciprocal online aggression is more likely to take place rather than cyber-victimization, which is characterized by a power differential between the bully and victim [17].

Second, when cyberbullying happens anonymously, there is a higher likelihood for other social media users to respond more aggressively towards the victimized individuals [18]. In turn, victims of cybervictimization, who used to be victimized offline, will eventually 'learn' from their past experiences that they are helpless, and incapable of effectively defending themselves, because fighting back will only amplify the intensity of the abuse [19]. In other words, there is a high possibility for every social media user to be a victim of cyber-victimization, and once they perceive themselves to be cyber-victimized, they might not be able to get out from the situation, because they eventually learned that they are helpless.

Furthermore, learned-helplessness (LH) have been reported to predict several negative traits among youths, ranging from academic procrastination [20] to the development of depressive mood [21] and depressive symptoms [22] furthermore, delayed or immediate depressive symptoms might lead to suicide ideation $[23,24]$. Accordingly, while some of the depression and suicidality were reported as the impact of the combination of cyber-victimization and offline victimization [25], but many of them were also caused by cybervictimization alone [26]. Hence, it can be assumed that the association among being cyberbullied, learnedhelplessness, and perceived depression is prevalent. Moreover, the increase in cyber-victimization related depression among youth since year 2006 [27, 28] indicates that there is a need to understand the contributing factors of prevalent cyber-victimization phenomenon in creating new and more severe victims [29].

This current study was initiated to investigate whether perceived cybervictimization will develop perceived depression through learned-helplessness. However, further review of the literature suggested that self-esteem plays important role in the studies phenomenon, for instance, only individuals with low score of self-esteem tend to experience being cyber-victimized [30], and that cyber-victimization contributes to lower self-esteem [31-33]. In order to understand the various directions of findings, it is imperative to look at self-esteem from the perspective that it has been shown to have trait components as well as state components [34-36]. These findings supported the hypothesis that having a perception of being cyber-victimized will predict one's state self-esteem, while studies some others indicated that certain level of trait self-esteem might determine whether one perceive that they are being cyber-victimized.

In the context of this study, state self-esteem is considered more imperative to study than trait self-esteem, which refers to an individual's accumulated lifelong perception of social inclusion and exclusion [37], because it is somehow more difficult to alter, while state self-esteem is a perception of changes in one's level of social inclusion, given a particular setting [38]. Hence, this study aims to investigate whether learned-helplessness and state self-esteem can explain the contribution of perceived cyber-victimization on perceived depression.

\section{REVIEWS OF LITERATURE}

The following subsections discuss the previous studies related to the variables and the interactions among them. Reviews of the following literatures were utilized to develop the hypothetical model to be tested in this current study.

\subsection{Perceived cyber-victimization and perceived depression}

Cyberbullying or Cyber-victimization refers to an intentional, aggressive and repetitive behavior perpetrated by a more powerful individual against someone more vulnerable using technology such as internet, social media and cellular phones [31], and some studies have reported its direct association with self-esteem in various directions. Studies on effects of cyberbullying reported stronger links between being victims of cyberbullying and perceived (self-reported) depression $[32,33]$ compared to traditional 
bullying [34] and that this relationship is stronger among girls [35, 36], although the gender differences are not significant at college level [33]. However, a study conducted in four universities in the USA revealed that college students who had been cyber-victimized are three times more likely than those who had never experience cyber-victimization to display symptoms of depression as delineated by DSM-IV [39]. The intrusive nature of cyberbullying, unlike traditional bullying that tends to end when the bully is not within the vicinity [40] seemingly predicts the escalating symptoms of depression over time [41] which could potentially lead to suicide ideation [26].

There seems to be no gender differences found at college level for the link between cybervictimization and (perceived) depression [33], suggesting that both male and female are equally susceptible to depression following cyber-victimization. Cyber-victimization among college students was a unique significant predictor of depression above and beyond traditional victimization. Specifically, adding cybervictimization to a model that already contained traditional victimization accounted for a greater percentage of the variance in depression, even when taking traditional victimization experiences into account, those who experience cyber-victimization are at even greater risk for developing symptoms of depression [33]. Furthermore, it would be more detrimental to students' social-emotional well-being than traditional victimization because it is a more persistent and pervasive form of aggression. This is because cybervictimization can occur frequently and is difficult to avoid, and the negative messages inherent in the victimization may be highly salient to the victim and difficult to counteract with positive messages, leading to reduced self-concept and subsequently higher levels of depression [42].

\subsection{State self-esteem as a mediator}

Before the time of social media, at the end of the $20^{\text {th }}$ century, internet was considered as a contributor to depression and lower self-esteem [43] and a few years later it was stated that internet communication provides perceived social support that significantly reduce depression and improve self-esteem [44]. However, the correlation between self-esteem and perceived depression has been established before the time of social media. For example, self-esteem primarily buffers the impact of depression that is caused by interpersonal relationship [45]. More recent studies reported clearer association between self-esteem and depression; for instance, a study among 594 adolescents reported that self-esteem was the most significant predictor for depressive symptoms [46]. In line with that, another study among 674 Mexican-American students reported that low self-esteem is the source of perceived depression [47]. In other words, their study indicated that individuals with low self-esteem are more susceptible to perceived depression.

In the context of cyber-victimization, Olweus [37] insisted that the term 'cyber' in cyber-victimization is overrated and is a low prevalence phenomenon, because the victims have been victimized even before they were cyberbullied. He suggested that the internet would neither create new victims nor new offenders because the social structure between the two has been established offline, and that social media is just a medium to continue their bullying behaviour. In line with that, a study among 90 British adolescents (16-19 years of age) suggested that self-esteem significantly predicted cyber-victimization, such that those with low self-esteem were most likely to report experience of cybervictimization [30].

The claims of Brewer and Kerslake [38] and Olweus [37] were denied by a larger scale study in Quebec ( $\mathrm{N}=6540)$, which confirmed that youths bullied via the internet presented a slightly higher intensity of psychological distress and lower self-esteem as compared to victims of other forms of bullying [48]43 Their further findings of the logistic regression suggested that the use of the Internet as a platform for harassment and mocking could lead to a greater feeling of overexposure than other forms of bullying; for that reason, individuals who were cyber-victimized may be more likely to develop psychological distress and low self-esteem.

Apart from that, self-esteem consists of trait and state components [36-38] whereby trait component is more innate and stable, whereas state self-esteem fluctuates following the social environment feedback of self-evaluation [48]. While self-esteem is how individuals feel about or evaluate themselves at a given point in time, state self-esteem refers to the temporary fluctuations in self-esteem [49]. A study among 1963 early teenagers in the United States indicated that less adequate self-esteem levels were found among the participants who were involved in cyber-victimization, both as offenders and as victims [50]. By pin-pointing inadequate self-esteem as the outcome, their study supplemented their previous one, which reported that cybervictimization contributes to negative emotional and psychological in general [22].

Furthermore, self-esteem as a mediator variable of depression has been reported as well; self-esteem mediated the contribution of body dissatisfaction on depressed mood among 4995 adolescents (1002 American and 3993 Koreans), adequate self-esteem level protected them from having depressed mood caused by body dissatisfaction [51]. On the other hand, a longitudinal study on 12,686 individuals in United States indicated that self-esteem did not play role in mediating the effect of parental socio-economic status on depression symptoms; instead, it was mediated by the prolonged stress due to poverty [52] However, the finding of 
Mossakowski can be considered arguable because he analyzed the mediation effect separately for his double mediation study ( $\mathrm{m} 1$ was self-esteem, and $\mathrm{m} 2$ was the length of poverty); because the interaction between selfesteem and length of poverty were not taken into consideration [53].

Related to cyber-victimization, studies of Hinduja and Patchin are mainly supported by the symbolic interaction theory $[54,55]$ which explains that individuals evaluate themselves based on their perception of another individuals' expectation on them. For instance, studies in school settings suggested that students' self-esteem is contingent on their own perception of teachers' expectancy towards them [56-58], and it might be mediated by other variables, such as locus of control [47] or social media usage [5]. In the context of this current study, social media users might have used the comments or other social feedback posted by their online peers to evaluate themselves; when they receive verbal aggression and other types of negative feedbacks, they will perceive that they are being cyber-victimized and in turn, this perception will affect their self-evaluation at the moment, and it predicts lower state self-esteem.

The aforementioned studies suggest that perceived cyber-victimization predicts state self-esteem, and that state self-esteem predicts perceived depression, which lead to the hypothesis that state self-esteem will play a mediating role on the relationship between perceived cyber-victimization and perceived depression. In other words, the higher the state self-esteem level, the less likely the perceived cyber-victimization will affect perceived depression among young adults.

Self-esteem as a mediator variable of depression has been reported in other studies as well; self-esteem mediated the contribution of body dissatisfaction on depressed mood among 4995 adolescents (1002 American and 3993 Koreans), adequate self-esteem level protected them from having depressed mood caused by body dissatisfaction [59]. On the other hand, a longitudinal study on 12,686 individuals in the United States indicated that self-esteem did not mediate the effect of parental socio-economic status on depression symptoms; instead, it was mediated by the prolonged stress due to poverty [53]. However, Mossakowski's did not report the interaction between his two variables (Self-eteem and prolonged stress due to poverty); the interaction between the two might explain the actual role of self-esteem in mediating the link.

\subsection{Learned-helplessness as a mediator}

The perceived-hopelessness of the victim is the most prevalent objective of the aggressors in the case of cyber-victimization, because prior to committing their aggression, the aggressors perceived power imbalance between aggressors and victims [60]. Although majority of these victims perceive that they have more autonomy in responding to the aggression such as ignoring or deleting the messages, or blocking the sender [61], adolescent users of social media tend to have the fear of missing out (FOMO), the desire to stay continually connected with others [62], which keeps them hooked onto social media and be exposed to all the negative feedbacks as well as verbal aggression towards them. Moreover, while the harassment initiated by the aggressor of cyber-victimization may have only been committed once, due to the permanence of accessibility, it can result in long term impacts of being cyber-victimized [26], and thereby intensifying the perception of being cyber-victimized.

Furthermore, a longitudinal study among 146 participants indicated that perceived cyber-victimization is also intensified by the perceived-anonymity of the offenders [7]. Another study by Zimmerman and Ybarra [20] among 126 undergraduate psychology students attending the University of North Florida showed that perceived anonymity increased the likelihood that individuals will aggress, and aggressive social modeling exacerbates this outcome in anonymous individuals. In other words, perceived cyber-victimization among victims is not only perceived to be intensified by the accessibility of social media, it is actually intensified by the other anonymous aggressors who might join the action victimizing them further. The development of intensity is also caused by the low tendency of the victims to report the aggression due to the fear of greater consequences should the aggressors hold grudges or take revenge for reporting them [63].

The escalation of the intensity of perceived cyber-victimization drives the victims to believe that they are helpless and hopeless. This phenomenon can be explained by the theory of hopelessness; building on the reformulated helplessness theory [64], the hopelessness theory [56] reduced the prominence of causal attributions (I am cyber-victimized), but instead characterize negative inferential styles in three forms of inferential tendencies in response to a negative event: (a) inferring stable and global causes, rather than unstable and specific causes for the event ("I am always worse than anyone else", instead of "There are things that others are better than me at."), (b) inferring negative consequences of the event (D attacks me because A, B, and C attacked me), and (c) inferring negative self-characteristics (I deserve to be victimized, that is why this will never stop). As explained, the continuous escalation of the perceived cyber-victimization intensity contributes to one's learned helplessness, which eventually leads one to hopelessness.

Related to the perceived depression, Nascimento, Walsh-Monteiro, and Gouveia [65] re-explained Seligman's theory of learned-helplessness [66] by stating that depression results from the idea that an action is useless, an idea that is generated due to the existence of uncontrollable situations, such as health 
issues, relationship issues, death and so forth. Another study by Mills, Azizoddin, Gholizadeh, Racaza and Nicassio [67] supported the statement by suggesting that helplessness fully mediated the relationship between pain and measures of anxiety, depression, and perceived stress among individuals who suffer from Systemic Lupus Erythematosus (SLE); in other words, learned-helplessness can even explain the contribution of pain on perceived depression and stress among SLE patients. In short, learned-helplessness is required before any symptom of depression can be perceived by individuals under certain level of stress.

\subsection{State self-esteem and learned-helplessness as double mediators}

Contextually, both digital and non-digital form of bullying contribute to a variety of negative outcomes including lower self-esteem, emotional disorders, and psychosocial problems that may follow adolescents into adulthood [57]. The decrease in state self-esteem and its correlation to psychological distress is also documented; three decades ago, a study among 78 students from New York University in Brockport suggested that self-esteem predicts learned-helplessness [58], whereby participants with high levels of selfesteem tend to perform better than those with low self-esteem when they face prolonged failure. Additionally, based on the hopelessness theory of depression [68], hopelessness might predict helplessness before leading one to depression. In line with that, Cakar and Savi studied 338 students of Celal Bayar University, Turkey, and reported that relationships between self-esteem and hopelessness was significant; self-esteem predicts the onset of hopelessness [69].

On the other hand, it was also reported that social media users with adequate self-esteem might respond similarly aggressive to users who tried to victimize them; some anonymous attack in the form of exhortations to suicide can be replied by a threat to find and kill the offender [70]. This phenomenon indicates that an adequate level of self-esteem might downplay the effect of perceived cyber-victimization on the learned-helplessness. Therefore, it is hypothesized that the contribution of perceived cyber-victimization on perceived depression is mediated by state self-esteem and learned-helplessness. The hypothetical framework can be illustrated as a double mediation model in Figure 1.

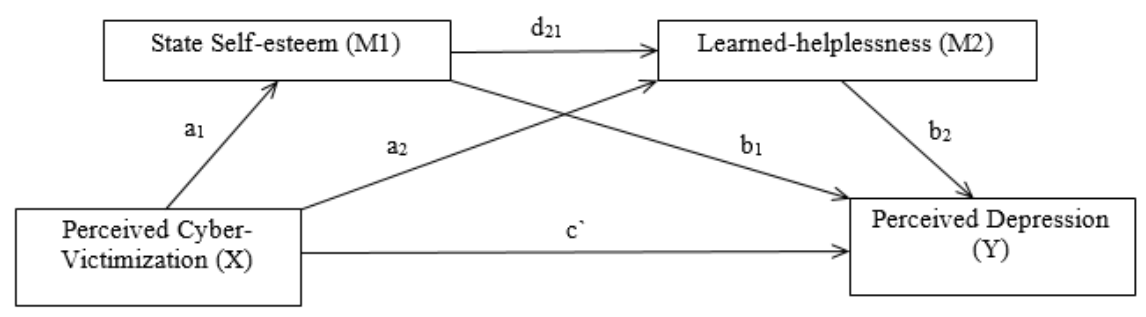

Figure 1. Double mediation model

\section{RESEARCH METHOD}

In order to test the hypothetical model illustrated in Figure 1, this study is designed as correlational study with survey method. Sample size was obtained from G*Power analysis; participants were gathered through purposive sampling method, by applying snowball method through the social media pages of the researchers. Standardized scales were obtained in order to measure each variables.

\subsection{Participants and Instruments}

Young adult social media users were recruited through haphazard and snowball sampling $(\mathrm{N}=116)$ to respond to the scales. A researcher-generated demographic questionnaire was prepared where participants were to detail their age, gender, major studied, country of study, and country of origin. Cyberbullying Victimization Scale [71] was used to measure participants' experience of being cyberbullied. The 27-item scale utilize a 5point Likert scale ranging from 1 (Strongly Disagree) to 5 (Strongly Agree) with a high Cronbach alpha of 0.95 [71]. Sample items include "I have received mean text messages on the mobile phone which made me uncomfortable" and "People have spread rumors about me online to damage my reputation".

State Self-Esteem Scale [72] was used to measure participants' current levels of self-esteem. The 20item scale utilize a 5-point Likert scale ranging from 1 (Strongly Disagree) to 5 (Strongly Agree) with a high Cronbach alpha of 0.92 . Items $2,4,5,7,8,10,13,15,16,17,18,19,20$ are reverse-scored. Sample items include "I feel confident about my abilities" and "I feel satisfied with the way my body looks right now". Sample of reverse-scored items include "I feel frustrated or rattled about my performance" and "I feel displeased with myself'. 
Learned Helplessness Scale [73] was used to measure participant's levels of learned helplessness. The 20-item scale utilize a 4-point Likert scale ranging from 1 (Strongly Disagree) to 4 (Strongly Agree) with a high Cronbach alpha of 0.947. Sample items include "I cannot find solutions to difficult problems." and "I don't place myself in situations in which I cannot resolve".

Beck Depression Inventory [68] was used to measure participant's levels of perceived depression. The 21-item scale utilize a set of four possible responses to each question. Sample response to questions include "My appetite is no worse than usual.", "My appetite is not as good as it used to be.", "My appetite is much worse now." and "I have no appetite at all anymore". The responses are scored from 0-3, when the total score is $0-10$, it is scored as not depressed, total scores of 11-16 is scored as "mild mood disturbance", total scores of 17-20 is scored as "borderline depressive symptoms", total scores of 21-30 is scored as "moderate depression", total scores of $31-40$ is scored as "severe depression", and total scores above 40 is scored as "extreme depression".

\subsection{Data collection procedure}

Participants were approached and asked to participate in the study via social media. Participants are given a link to an online Google form to fill. After reading and agreeing to the informed consent, Participants proceed to fill up the rest of the questionnaire in the following order: researcher generated demographic questionnaire, the CyberBullying Victimization Scale, State Self-Esteem Scale (SSES), Learned Helplessness Scale, and lastly Beck's Depression Inventory. The responses were submitted, and participants were thanked. On average participants took no longer than 45 minutes to complete the online questionnaire.

\section{RESULTS AND ANALYSIS}

Multiple regression method was utilized to analyze the collected data. The analyses were conducted by using PROCESS Macro version 3 [74] for SPSS 20, in order to conduct the bootstrap method to test the double mediation. Bootstrap method was utilized in the data analyses because it is one of the most robust method to analyze multiple regression without conducting assumption tests [74].

\subsection{The total effect of perceived cyber-victimization on perceived depression}

Table 1 illustrates the total effect of perceived cyber-victimization on perceived depression. In this table, the predictor was taken as a model, where the mediators are not controlled.

Table 1. Total effect of the model Perceived Cyber-victimization and Perceived Depression, $\mathrm{N}=104$

\begin{tabular}{cccccccccc}
\hline & & & & & & \multicolumn{4}{c}{$95 \%$ CI } \\
Effect & coeff & R-sq & F & Df1 & Df 2 & t & p & Lower & Upper \\
\hline Total & 0.321 & 0.259 & 36.108 & 1.000 & 103.000 & 6.01 & 0.000 & 0.215 & 0.428 \\
\hline
\end{tabular}

Outcome variable: Perceived depression

Perceived cyber-victimization as a model significantly predicts perceived-depression $[\mathrm{F}(1,103)$ $=36.11, \mathrm{p}<0.001]$, and explains $25.96 \%$ of the variance $\left(\mathrm{R}^{2}=.26\right)$. As a predictor, perceived cyber-victimization significantly predicts perceived-depression $[\beta=0.32, \mathrm{t}(103)=6.01, \mathrm{p}<0.001]$. This indicates that as perceived cyber-victimization increases by one point, perceived-depression significantly increases by 0.32 points, and the predictor can explain $26 \%$ of the variance of the increment.

\subsection{Indirect effects}

The following Table 2 illustrates the results of the bootstrapping analyses as indirect effects of this current study.

Table 2. Relationship between Perceived Cyber-victimization and Perceived Depression, with State Self-Esteem and Learned Helplessness as mediators, N=104

\begin{tabular}{|c|c|c|c|c|c|}
\hline \multirow[b]{2}{*}{ Effect } & & \multirow[b]{2}{*}{ Effect } & \multirow[b]{2}{*}{ BootSE } & \multicolumn{2}{|c|}{$95 \% \mathrm{CI}$} \\
\hline & & & & Lower & Upper \\
\hline Direct & Predictor $\rightarrow$ Outcome $(\mathrm{p}=.029)$ & 0.108 & 0.046 & 0.131 & 0.309 \\
\hline Ind1 & Predictor $\rightarrow \mathrm{M} 1 \rightarrow$ Outcome & 0.101 & 0.035 & 0.040 & 0.179 \\
\hline Ind 2 & Predictor $\rightarrow \mathrm{M} 2 \rightarrow$ Outcome & 0.054 & 0.028 & 0.009 & 0.116 \\
\hline Ind3 & Predictor $\rightarrow \mathrm{M} 1 \rightarrow \mathrm{M} 2 \rightarrow$ Outcome & 0.058 & 0.024 & 0.020 & 0.114 \\
\hline
\end{tabular}

Predictor $=$ perceived cyber-victimization

M1 = state self-esteem

M2 = learned-helplessness

Outcome $=$ perceived-depression 
The indirect effect of perceived cyber-victimization on perceived-depression through state self-esteem was significant, $b=0.10$ as the bias-corrected bootstrap confidence interval based on 5000 samples does not contain zero, [0.040, 0.179], indicating that mediation likely occurs. Furthermore, the second indirect effect is the between perceived cyber-victimization and perceived-depression through learned helplessness. The relationship was significant, $b=0.54$ as the bias-corrected bootstrap confidence interval based on 5000 samples does not contain zero, $[0.009,0.116]$, indicating that mediation likely occurs. The double mediation also likely occurs when the third indirect effect, which is between perceived cyber-victimization and perceived-depression through state self-esteem and learned helplessness is significant, $b=0.06$ as the bias-corrected bootstrap confidence interval based on 1000 samples does not contain zero, [0.020, 0.114], indicating that the double mediation likely occurs. Additionally, the direct effect of the predictor on the outcome (controlling for the first and second mediators) showed that the predictor is no longer significant in 99\% confidence interval $(\mathrm{p}=.029)$. In other words, all the hypotheses of this current study are supported.

\subsection{Supplementary analyses}

Table 3 and Table 4 depict the supplementary analyses conducted to supplement the result of the main analyses. Table 3 shows the total effect of state self-esteem on perceived-depression, and Table 4 illustrates the mediation role of learned-helplessness.

Table 3. Total effect of the model State Self-esteem and Perceived Depression, $N=104$

\begin{tabular}{cccccccccc}
\hline & & & & & \multicolumn{3}{c}{$95 \%$ CI } \\
Effect & coeff & R-sq & F & Df1 & Df 2 & t & p & Lower & Upper \\
\hline St SE & -0.30 & 0.55 & 61.85 & 2.00 & 102.00 & 1.81 & 0.00 & -0.46 & -0.15 \\
\hline Outcome variable: Perceived depression & & & &
\end{tabular}

State self-esteem as a model significantly predicts perceived-depression, $[\mathrm{F}(2,102)=61.85$, $\mathrm{p}<0.001]$, as well as explaining $54.81 \%$ of the variance $\left(\mathrm{R}^{2}=0.55\right)$. As a predictor, state self-esteem model significantly reduces perceived-depression $[\mathrm{b}=-0.30, \mathrm{t}(102)=1.81, \mathrm{p}<0.001]$. This indicates that when perceived state self-esteem increases by one point, perceived-depression significantly decreases by 0.30 points, and the predictor can explain most of the of the variance of the reduction (about 55\%). Before analyzing further on the mediation role of learned-helplessness, another analysis on the prediction of state self-esteem on learnedhelplessness is reported in Table 4.

Table 4. Contribution of the state self-esteem on learned-helplessness, $\mathrm{N}=104$

\begin{tabular}{|c|c|c|c|c|c|c|c|c|c|}
\hline & & & & & & & & $95 \%$ & \\
\hline Effect & coeff & R-sq & $\mathrm{F}$ & Df1 & Df 2 & $\mathrm{t}$ & $\mathrm{p}$ & Lower & Upper \\
\hline St SE & -0.674 & 0.543 & 122.560 & 1.000 & 103.000 & -11.071 & $>0.000$ & -0.794 & -0.553 \\
\hline
\end{tabular}

As shown in Table 4, self-esteem is a significant negative predictor for learned-helplessness $[\mathrm{F}(1,103)=122.56, \mathrm{p}<0.001]$, the power of its contribution is considered strong $(\beta=-0.67)$ and it explains $54 \%$ of the variance $\left(\mathrm{R}^{2}=0.543\right)$. In other words, when self-esteem is increased by one point, there is a $54 \%$ chances of learned-helplessness to be reduced by 0.67 points. The mediation role of learned-helplessness is summarized in Table 5.

Table 5. Relationship between state self-esteem and perceived depression, with learned-helplessness as a mediator, $\mathrm{N}=104$

\begin{tabular}{|c|c|c|c|c|c|}
\hline \multirow[b]{2}{*}{ Effect } & & \multirow[b]{2}{*}{ Effect } & \multirow[b]{2}{*}{ SE/BootSE } & \multicolumn{2}{|c|}{$95 \% \mathrm{CI}$} \\
\hline & & & & Lower & Upper \\
\hline Direct & Predictor $\rightarrow$ Outcome & -0.304 & 0.078 & -0.459 & -0.149 \\
\hline Indirect & Controlling for $\mathrm{M}$ & -0.242 & 0.080 & -0.410 & -0.095 \\
\hline
\end{tabular}

Table 5 shows that he indirect effect of self-esteem on perceived-depression through state learnedhelplessness was significant, $\mathrm{b}=-.2419$ as the bias-corrected bootstrap confidence interval based on 5000 samples does not contain zero, [-.4097, -.0947], indicating that learned-helplessness is likely to mediate the contribution of state self-esteem in decreasing perceived depression. 
The next supplementary analysis is about the relationship between the perceived cyber-victimization on state self-esteem. This link holds an important information on the nature of how the perception of being cyberbullied might affect one's self-esteem. The result is summarized in Table 6.

Table 6. Relationship between perceived cyber-victimization and state self-esteem, N=104

\begin{tabular}{cccccccccc}
\hline Effect & coeff & R-sq & F & Df1 & Df 2 & t & P & Lower & Upper \\
\hline Prc CV & -.35 & .19 & 24.68 & 1.00 & 103.00 & -4.97 & .00 & -.49 & -.21 \\
\hline Outcome & variable: State self-esteem & & & & &
\end{tabular}

Outcome variable: State self-esteem

Perceived cyber-victimization significantly predicts state self-esteem, $[\mathrm{F}(1,103)=24.68, \mathrm{p}<.001]$, as well as explaining $19 \%$ of the variance $\left(\mathrm{R}^{2}=.19\right)$. As a predictor, perceived cyber-victimization negatively contributes to state self-steem $[\mathrm{b}=-.35, \mathrm{t}(103)=-4.97, \mathrm{p}<.001]$. This indicates that when perceived cybervictimization increases by one point, state self-esteem significantly decreases by 0.35 points. However, the predictor can explain less than $20 \%$ of the variance $\left(\mathrm{R}^{2}=.19\right)$. The finding suggests that despite the negative contribution of perceived cyber-victimization is strong, the chance of having one's state selfesteem decreased by being cyberbullied is less than $20 \%$.

\section{DISCUSSION}

The aim of this study was to investigate whether learned-helplessness and state self-esteem can explain the contribution of perceived cyber-victimization on perceived depression. Past studies in the area of cyberbullying have consistently shown that individuals who perceive themselves to be cyberbullied are more likely to experience symptoms of depression $[32,33]$. Similarly, the results from this study indicated that perceived cyber-victimization as a model significantly predicts learned-helplessness through lowering state self-esteem and increasing learned-helplessness. This finding is supported by the hopelessness theory of depression [68] that helplessness might predict hopelessness before leading one to depression. This is because social media users are less likely to experience perceived depression as a direct outcome of perceived cybervictimization, because learned helplessness usually develops over time, which subsequently results in perceived depression. Moreover, the tendency to experience learned helplessness can be lowered by adequate state self-esteem, indicating that perceived cyber-victimization cannot directly explain perceived depression as an outcome. This finding also supports the reports of Cakar and Savi (2014) that decreased selfesteem predicts the onset of hopelessness [69].

Nevertheless, there are several important findings apart from the fact that all the hypotheses are supported. First, although the first hypothesis was supported, the total effect of the model of perceived cybervictimization significantly predicts perceived depression, it can only explain $26 \%$ of the variance $\left(\mathrm{R}^{2}=.26\right)$, which means that perceived cyber-victimization could not be the dominant factor of perceived depression; apart from the perception of being cyberbullied, state self-esteem, or learned-helplessness, there are still many possible factors involved in the development of perceived depression among social media users. Other factors that might be involved are for example: prolonged poverty [53], experience of being victimized offline [33], or reduced self-concept [42]. The small size of the $\mathrm{R}^{2}$ might also support the claim of Olweus [37], who stated that cyberbullying is generally less prevalent than offline bullying, because those who are cyber-victimized are the same people who got victimized offline.

The second important finding is that the significance of the direct effect of perceived cybervictimization was dropped when controlling for the mediators (state self-esteem and learned-helplessness). As compared to individuals with inadequate self-esteem, individuals with adequate self-esteem tend to have more self-respect and are more assertive [65]. This suggests that perceived cyberbullying will not necessarily lead to perceived depression if they do not value themselves negatively and/or learn that they are helpless. This finding is in line with the study of Choi and Choi [69], that adequate self-esteem level protects individuals from having depressive mood. However, it has been found that cyberbullying is a stronger predictor of depressive symptoms than offline bullying due to its prolonged accessibility [26], which intensified their experience of being cyberbullied and eventually increases learned-helplessness and decreases state self-esteem. Thus, findings of this study also support the report of Przybylski, et al. [72] that the FOMO among social media users could be a contributing factor of perceived depression as a result of cybervictimization.

From the supplementary analysis, it was also indicated that state self-esteem as a model has a significant negative relationship with perceived depression, and it can explain more than half of the variance $\left(\mathrm{R}^{2}=54.81\right)$; moreover, the power of its contribution is considered strong $(\beta=-0.30)$. It indicates that the

Int. J. Eval. \& Res. Educ. Vol. 8, No. 4, December 2019: 563 - 574 
presence of adequate state self-esteem might protect individuals from falling into perceived depression. State self-esteem also significantly decrease learned helplessness by more than $50 \%$ chance $\left(\mathrm{R}^{2}=.54\right)$, and the contribution is considered strong, because one-point increment of state self-esteem might reduce learnedhelplessness by 0.67 points. Therefore, learned-helplessness significantly changes the strength of state selfesteem in reducing perceived depression; social media users persistently feel cyberbullied due to their high frequency of exposure to the derogatory comments or posts directed towards them, resulting in increased perceived cyber-victimization, which eventually reduce the adequacy of their state self-esteem, increase their learned-helplessness, which will subsequently increase perceived depression. This finding supports the study of Young et al. [22] that social media users with adequate self-esteem who have not learned that they are helpless might even respond aggressively to those who attempted to victimize them.

Moreover, the second supplementary analysis indicated that the prevalence of having perceived cybervictimization reducing state self-esteem is not less than $20 \%$. This means that less than $20 \%$ of state self-esteem decrease can be explained by the increment of perceived cyber-victimization, and that there is a larger part of state self-esteem that is independent from being cyberbullied. This finding is in line with the report of Brewer and Kerslake [38] that only individuals with low score of self-esteem tend to experience being cybervictimized. Apart from that, past research has shown that self-esteem serves as protective factor of psychological well-being [65, 67] and life satisfaction [75]. The implication of the statement is that improving state self-esteem can reduce the negative effect of being cyberbullied. The implication is supported by the report of Young and colleagues [70] that individuals with adequate level of self-esteem are more likely respond similarly aggressive to the offender, and do not perceive themselves to be helpless.

\subsection{Practical implications}

This study contributes to the existing literature on cyber-victimization by examining the empirical data on the mediating roles of learned helplessness and state self-esteem. While one-point decrease of state self-esteem might explain more than $50 \%$ chances of the 0.67 points increment of learned helplessness, most of the decrease in self-esteem has nothing to do with cyberbullying; the perceived cyber-victimization can only explain $19 \%$ of the change in state self-esteem.

The practical implication of this finding is that it is imperative for educators or parents to pay extra effort in creating state self-esteem stability for the younger generation in order for them to develop more stable adequate self-esteem. As suggested by Prihadi and Chua [5], educators might utilize social media such as Facebook to improve self-esteem adequacy and general responsibility among adolescents. Knowing that stable adequate self-esteem protects young social media users from learned-helplessness and perceiveddepressions caused by perceived cyber-victimization, it is also important for educational stakeholders to be wiser in in strategizing their method of assigning students to their respective classrooms; some studies, such as Prihadi et al. [64, 65] as well as Ismail and Majeed [76] suggested that assigning students to specific classrooms based on their previous academic results might jeopardize their self-esteem adequacy in the long run. For example, students with good academic achievement who are grouped together tend to have higher self-esteem; whereas students with poor academic achievement who are grouped together tend to have lower self-esteem. Thus, applying mixed-ability grouping might further protect younger social media users from negative effect of perceived cyber-victimization.

\section{CONCLUSION}

This study provides insights to educators and education stakeholders that while perceived depression among university students can be considered prevalent, their social media behavior should not be taken as the culprit. Findings of study indicated that negative experience in social media (in the form of being cybervictimized) will not predict their perceived depression, unless they learned that they are helpless, and that their state self-esteem is shaken by the experience. Moreover, findings of this study suggested that perceived cyber-victimization as a model can only explain $26 \%$ of perceived depression cases, indicating that there are still other risk factors of perceived depression beyond cyber-victimization that need to be studied. On the other hand, state self-esteem explains $55 \%$ of perceived depression. Thus, other factors such as social economic status, education levels of parents, perceived parenting styles of the parents, and any other factors that might lead to different attitude towards self should be examined in future studies

Additionally, findings of this current study could have been more generalizable by collecting data from a more heterogeneous population. Due to the haphazard sampling method, most of the participants were highly educated and reside in urban area. Their reaction towards cyberbullying attempts might be different from young adults who are not exposed to higher education or live in rural areas. Thus, studies with a larger sample size and a more heterogeneous sample are highly suggested. Furthermore, a qualitative version of this current study is also highly suggested in order to obtain deeper understanding on how state self-esteem and 
learned-helplessness mediated the contribution of perceived cyber-victimization on perceived depression; moreover, qualitative studies will also help the stakeholders to gain deeper insights on the factors that encourages a social media user to become a cyberbully.

Other factors related to the usage of social media, such as the frequency of usage, types of social media, preferred content to comment to, as well as attitude towards online anonymity are also suggested for future studies, together with online sharing behavior that might put certain social media users vulnerable to cyberbullies. Hence, the roles of the aforementioned factors in developing (or preventing) perceived depression is imperative to be studied in order to prevent further negative events related to cyber-victimization and depression.

\section{ACKNOWLEDGEMENTS}

This study is supported by Internal Research Grant Scheme (IRGS) from the Research Management Center of ELM Graduate School, HELP University, Kuala Lumpur, Malaysia.

\section{REFERENCES}

[1] A. M. Kaplan and M. Haenlein, "Users of the world, unite! The challenges and opportunities of Social Media," Business horizons, vol. 53(1), pp. 59-68, 2010.

[2] K. Erwin and B. Shatto, "Moving on From Millennials: Preparing for Generation Z," The Journal of Continuing Education in Nursing, vol. 47(6), pp. 253-254, 2016.

[3] T. Heiman and D. Olenik-Shemesh, "Cyberbullying Victimization in Adolescents as Related to Body Esteem, Social Support, and Social Self-Efficacy," Journal of interpersonal violenc, vol. 32(1), pp. 23-48, 2017.

[4] T. M. Dumas, P. A. Giuliettia, J. P. Davi and M. Maxwell-Smith, "Lying or longing for likes? Narcissism, peer belonging, loneliness and normative versus deceptive like-seeking on Instagram in emerging adulthood," Computers in Human Behavior, no. 71, pp. 1-10, 2017.

[5] K. Prihadi and M. Chua, "Students' Self-esteem at School: The Risk, the Challenge, and the Cure," Journal of Education and Learning, vol. 1(6), pp. 1-14, 2012

[6] M. Tiggemann, S. Hayden, Z. Brown and J. Veldhuis, "The effect of Instagram "likes" on women's social comparison and body dissatisfaction," Body Image, vol. 26, pp. 90-97, 2018.

[7] C. P. Barlett, D. A. Gentile and C. Chew, "Predicting cyberbullying from anonymity," Psychology of Popular Media Culture, vol. 2(5), p. 171, 2016.

[8] M. Arntfield, "Towards a cybervictimology: Cyberbullying, routine activities theory, and the anti-sociality of social media," Canadian Journal of Communication, vol. 3, 2015.

[9] A. Karmen, Crime victims: An introduction to victimology (6th edition), Belmont, CA: Thomson-Wadsworth, 2007.

[10] B. Turvey, Forensic victimology: Examining violent crime victims in investigative and legal, Waltham, MA: Academic Press., 2013.

[11] L. E. Cohen and M. Felson, "Social change and crime rate trends: A routine activity approach," American sociological review, pp. 588-608, 1979.

[12] E. B. Dowdell, A. W. Burgess and J. R. Flore, "Online social networking patterns among adolescents, young adults, and sexual offenders," AJN the American Journal of Nursing, vol. 111(7), pp. 28-36, 2011.

[13] C. J. Ferguson, "Sexting behaviors among young Hispanic women: Incidence and association with other high-risk sexual behaviors," Psychiatric Quarterly, vol. 82(3), pp. 239-243, 2011.

[14] C. P. Barlett, "Predicting adolescent's cyberbullying behavior: A longitudinal risk analysis," Journal of adolescence, vol. 41, pp. 86-95, 2015.

[15] M. Arntfield, Cybercrime \& cyberdeviance, Criminology: A Canadian perspective, pp. 500-516, 2014

[16] S. Hinduja and J. W. Patchin, "Cyberbullying: An exploratory analysis of factors related to offending and victimization," Deviant behavior, vol. 29(2), pp. 129-156, 2008.

[17] M. Ito, Hanging out, messing around, and geeking out: Kids living and learning with new, Cambridge, MA: MIT Press, 2013.

[18] W. V. Pelfrey Jr and N. L. Weber, "Keyboard gangsters: Analysis of incidence and correlates of cyberbullying in a large urban student population," Deviant Behavior, vol. 34(1), pp. 68-84, 2013.

[19] D. M. Law, J. D. Shapka, J. F. Domene and M. H. Gagné, "Are cyberbullies really bullies? An investigation of reactive and proactive online aggression," Computers in Human Behavior, vol. 28(2), pp. 664-672, 2012.

[20] A. G. Zimmerman and G. J. Ybarra, "Online aggression: The influences of anonymity and social modeling," Psychology of Popular Media Culture, vol. 5(2), pp. 181, 2016.

[21] M. K. Martinez-Dick, "The effect of bystander behavior and victim response on teenage girls' perceptions of chat room cyberbullying," Illinois State University, 2013.

[22] K. Prihadi, C. Y. H. Tan, R. T. S. Tan, P. Yong, J. H. E. Yong, S. Tinagaran, C. L. Goh and Y. J. Tee, "Mediation Role of Locus of Control on the Relationship of Learned-Helplessness and Academic Procrastination," International Journal of Evaluation and Research in Education, vol. 7(2), pp. 87-93, 2018.

[23] S. Eden, T. Heiman and D. Olenik-Shemesh, "Teachers' perceptions, beliefs and concerns about cyberbullying," British Journal of Educational Technology, vol. 44(6), pp. 1036-1052, 2013. 
[24] S. Hinduja and J. W. Patchin, "Cyberbullying fact sheet: A brief review of relevant legal and policy issues," 2009. [Online]. Available: http://www. cyberbullying.us/cyberbullying_legal_issues.pdf.

[25] R. Didden, R. H. Scholte, H. Korzilius, J. M. De Moor, A. Vermeulen, M. O’Reilly, R. Lang and G. E. Lancioni, "Cyberbullying among students with intellectual and developmental disability in special education settings," Developmental neurorehabilitation, vol. 12(3), pp. 146-151, 2009.

[26] D. L. Espelage, S. Low and L. De La Rue, "Relations between peer victimization subtypes, family violence, and psychological outcomes during early adolescence," Psychology of Violence, vol. 2(4), pp. 313, 2012.

[27] R. Slonje and P. K. Smith, "Cyberbullying: Another main type of bullying?," Scandinavian journal of psychology, vol. 49(2), pp. 147-154, 2008.

[28] R. A. Bonanno and S. Hymel, "Cyber bullying and internalizing difficulties: Above and beyond the impact of traditional forms of bullying," Journal of youth and adolescence, vol. 42(5), pp. 685-697, 2013.

[29] J. W. Patchin and S. Hinduja, "Bullies move beyond the schoolyard: A preliminary look at cyberbullying," Youth violence and juvenile justice, vol. 4(2), pp. 148-169, 2006.

[30] M. L. Ybarra, K. J. Mitchell, J. Wolak and D. Finkelhor, "Examining characteristics and associated distress related to Internet harassment: findings from the Second Youth Internet Safety Survey," Pediatrics, vol. 118(4), pp. E1169-E1177, 2006.

[31] J. M. Cénat, M. Hébert, M. Blais, F. Lavoie, M. Guerrier and D. Derivois, "Cyberbullying, psychological distress and self-esteem among youth in Quebec schools," Journal of affective disorders, vol. 169, pp. 7-9, 2014.

[32] A. L. Palermiti, R. Servidio, M. G. Bartolo and A. Costabile, "Cyberbullying and self-esteem: An Italian study," Computers in Human Behavior, vol. 69, pp. 136-141, 2017.

[33] S. Hinduja and J. W. Patchin, "Bullying, cyberbullying, and suicide," Archives of suicide research, vol. 14(3), pp. 206-221, 2010.

[34] M. B. Donnellan, D. A. Kenny, K. H. Trzesniewski, R. E. Lucas and R. D. Conger, "Using trait-state models to evaluate the longitudinal consistency of global self-esteem from adolescence to adulthood," Journal of research in personality, vol. 46(6), pp. 634-645, 2012.

[35] D. A. Kenny and A. Zautra, "Trait-state models for longitudinal data," in Decade of behavior. New methods for the analysis of change, Washington, DC, American Psychological Association., 2001, pp. 243-263.

[36] J. Wagner, O. Lüdtke and U. Trautwein, "Self-esteem is mostly stable across young adulthood: Evidence from latent STARTS models," Journal of Personality, vol. 84(4), pp. 523-535, 2016.

[37] D. Olweus, "Cyberbullying: An overrated phenomenon?," European Journal of Developmental Psychology, vol. 9(5), pp. 520-538, 2012.

[38] G. Brewer and J. Kerslake, "Cyberbullying, self-esteem, empathy and loneliness," Computers in human behavior, vol. 48, pp. 255-260, 2015.

[39] M. R. Leary, E. S. Tambor, S. K. Terdal and D. L. Downs, "Self-esteem as an interpersonal monitor: the sociometer hypothesis," Journal of personality and social psychology, vol. 68(3), pp. 518, 1995.

[40] T. Pyszczynski, J. Greenberg, S. Solomon, J. Arndt and J. Schimel, "Why do people need self-esteem? A theoretical and empirical review," Psychological bulletin, vol. 130(3), pp. 435, 2004.

[41] E. Whittaker and R. M. Kowalski, "Cyberbullying via social media," Journal of School Violence, vol. 14(1), pp. 11-29, 2015.

[42] C. A. Rose and B. M. Tynes, "Longitudinal associations between cybervictimization and mental health among US adolescents," Journal of Adolescent Health, vol. 57(3), pp. 305-312, 2015.

[43] J. E. Tennant, M. K. Demaray, S. Coyle and C. K. Malecki, "The dangers of the web: Cybervictimization, depression, and social support in college students," Computers in Human Behavior, vol. 50, pp. 348-357, 2015.

[44] S. Perren, J. Dooley, T. Shaw and D. Cross, "Bullying in school and cyberspace: Associations with depressive symptoms in Swiss and Australian adolescents," Child and adolescent psychiatry and mental health, vol. 4(1), pp. $28,2010$.

[45] C. F. Brown, M. K. Demaray and S. M. Secord, "Cyber victimization in middle school and relations to social emotional outcomes," Computers in human behavior, vol. 35, pp. 12-21, 2014.

[46] R. M. Kowalski, G. W. Giumetti, A. N. Schroeder and M. R. Lattanner, "Bullying in the digital age: A critical review and meta-analysis of cyberbullying research among youth," Psychological bulletin, vol. 140(4), pp. 1073, 2014.

[47] U. Orth, R. Robins, K. Widaman and R. Conger, "Is low self-esteem a risk factor for depression? Findings from a longitudinal study of Mexican-origin youth," Developmental Psychology, vol. 50, pp. 622-633, 2014.

[48] E. M. Selkie, R. Kota, Y. F. Chan and M. Moreno, "Cyberbullying, depression, and problem alcohol use in female college students: a multisite study," Cyberpsychology, vol. 18(2), pp. 79-86, 2015.

[49] A. G. Dempsey, M. L. Sulkowski, R. Nichols and E. Storch, "Differences between peer victimization in cyber and physical settings and associated psychosocial adjustment in early adolescence," Psychology in the Schools, vol. 46, (10), pp. 962-972, 2009.

[50] R. R. Landoll, A. M. La Greca, B. S. Lai, S. F. Chan and W. M. Herge, "Cyber victimization by peers: Prospective associations with adolescent social anxiety and depressive symptoms," Journal of adolescenc, vol. 42, pp. 77-86, 2015.

[51] J. D. Lipton, "Combating cyber-victimization," Berkeley Tech, pp. 1103, 2011.

[52] R. Kraut, M. Patterson, V. Lundmark, S. Kiesler, T. Mukophadhyay and W. Scherlis, "Internet paradox: A social technology that reduces social involvement and psychological well-being?," American psychologist, vol. 53(9), pp. 1017, 1998. 
[53] L. H. Shaw and L. M. Gant, "In defense of the Internet: The relationship between Internet communication and depression, loneliness, self-esteem, and perceived social support," Internet Research, vol. 28(3), pp. 157-171, 2004.

[54] M. A. Longmore and A. DeMaris, "Perceived inequity and depression in intimate relationships: The moderating effect of self-esteem," Social Psychology Quarterly, pp. 172-184, 1997.

[55] A. Babore, C. Trumello, C. Candelori, M. Paciello and L. Cerniglia, "Depressive symptoms, self-esteem and perceived parent-child relationship in early adolescence," Frontiers in psychology, vol. 7, pp. 982, 2016.

[56] Z. Ismail and A. Majeed, "Student Self Esteem and Their Perception of Teacher Behavior: A Study of Class Grouping System in Pakistan," International Journal of Business and Social Science, vol. 2(16), 2011.

[57] D. McGillicuddy and D. Devine, "“Turned off" or "ready to fly"-Ability grouping as an act of symbolic violence in primary school," Teaching and Teacher Education, vol. 70, pp. 88-99, 2018.

[58] K. Prihadi, N. I. Hairul and J. Hazri, "Students' self-esteem and their perception of teacher behavior: a study of between-class ability grouping," Electronic Journal of Research in Educational Psychology, 2010.

[59] K. Geukes, S. Nestler, R. Hutteman, M. Dufner, A. C. Küfner, B. Egloff and M. D. D. J. Back, "Puffed-up but shaky selves: State self-esteem level and variability in narcissists," Journal of Personality and Social Psychology, vol. 112(5), pp. 769, 2017.

[60] T. F. Heatherton and J. Polivy, "Development and validation of a scale for measuring state self-esteem," Journal of Personality and Social psychology, vol. 60(6), pp. 895, 1991.

[61] E. Choi and I. Choi, "The associations between body dissatisfaction, body figure, self-esteem, and depressed mood in adolescents in the United States and Korea: A moderated mediation analysis," Journal of adolescence, vol. 53, pp. 249-259, 2016.

[62] K. N. Mossakowski, "Disadvantaged Family Background and Depression among Young Adults in the United States: The Roles of Chronic Stress and Self-Esteem," Stress and Health, vol. 31(1), pp. 52-62, 2013.

[63] H. Blumer, Society as symbolic interaction, Contemporary Sociological Thought, pp. 91, 1962.

[64] C. H. Cooley, "Looking-glass self," The production of reality: Essays and readings on social interaction, vol. $6,1902$.

[65] R. S. Tokunaga, "Following you home from school: A critical review and synthesis of research on cyberbullying victimization," Computers in human behavior, vol. 26(3), pp. 277-287, 2010.

[66] M. E. Seligman, "Learned helplessness," Annual review of medicine, vol. 23(1), pp. 407-412, 1972.

[67] B. Joel, G. Marie, B. Jon, M. Ted, T. Barbara, W. L. Wendy and M. Alan, "The roles of self-esteem and selfconsciousness in the Wortman-Brehm model of reactance and learned helplessness," Journal of Personality and Social Psychology, vol. 45(1), pp. 199, 1983.

[68] K. Prihadi, N. I. Hairul and J. Hazri, "Mediation effect of Locus of Control on the causal relationship between students' perceived teachers' expectancy and self-esteeem," Electronic Journal of Research in Educational Psychology, vol. 12(2), 2012.

[69] E. Choi and I. Choi, "The associations between body dissatisfaction, body figure, self-esteem, and depressed mood in adolescents in the United States and Korea: A moderated mediation analysis," Journal of adolescence, vol. 53, pp. 249-259., 2016.

[70] C. Langos, "Cyberbullying: The challenge to define," Cyberpsychology, Behavior, and Social Networking, vol. 15(6), pp. 285-289, 2012.

[71] E. K. Corby, M. Campbell, B. Spears, P. Slee, D. Butler and S. Kift, "Students' perceptions of their own victimization: A youth voice perspective," Journal of school violence, vol. 15(3), pp. 322-342, 2016.

[72] A. K. Przybylski, K. Murayama, C. R. DeHaan and V. Gladwell, "Motivational, emotional, and behavioral correlates of fear of missing out," Computers in Human Behavior, vol. 29(4), pp. 1841-1848, 2013.

[73] K. N. Sobba, R. A. Paez and T. Ten Bensel, "Perceptions of cyberbullying: an assessment of perceived severity among college students," TechTrends, vol. 61(6), pp. 570-579, 2017.

[74] D. T. Rose and L. Abramson, "IX developmental predictors cf depressive cognitive style: research and theory," Developmental perspectives on depression, vol. 4, pp. 323, 1992.

[75] L. Y. Abramson, M. E. Seligman and J. D. Teasdale, "Learned helplessness in humans: Critique and reformulation," Journal of abnormal psychology, vol. 87, pp. 49, 1978.

[76] R. T. Liu, E. M. Kleiman, B. A. Nestor and S. M. Cheek, "The hopelessness theory of depression: A quarter-century in review," Clinical Psychology: Science and Practice, vol. 22(4), pp. 345-365., 2015. 